\title{
FENOLOGIA E ACÚMULO DE GRAUS-DIA DA VIDEIRA 'NIAGARA ROSADA' CULTIVADA AO NOROESTE DO ESTADO DE SÃO PAULO ${ }^{1}$
}

\author{
MARCO ANTONIO TECCHIO ${ }^{2,}$ MAURILO MONTEIRO TERRA ${ }^{2}$, \\ MARA FERNANDES MOURA², ERASMO JOSÉ PAIOLI-PIRES ${ }^{2}$
}

RESUMO - Este trabalho teve por objetivo avaliar a influência dos porta-enxertos 'IAC 766', 'IAC 572', 'IAC 313' e 'IAC 571-6' na duração dos estádios fenológicos e no acúmulo de graus- dia pela videira 'Niagara Rosada', cultivada em Votuporanga-SP. O delineamento estatístico utilizado foi em blocos inteiramente casualizados, com parcelas subdivididas, cinco repetições, sendo as parcelas representadas pelos porta-enxertos, e as subparcelas, pelos dois ciclos de produção. Após a poda da videira, foram realizadas avaliações dos estádios fenológicos, utilizando-se do critério de Eichhon e Lorenz (1984). Baseado nos estádios fenológicos, calculou-se a duração dos períodos: poda ao início da brotação; poda ao início do florescimento; poda ao início da frutificação; poda ao início da maturação dos cachos; poda ao início da colheita. Tomando-se por base a duração do ciclo da videira e as temperaturas médias diárias, calculou-se o acúmulo de graus-dia. Obteve-se maior duração do ciclo e do acúmulo de graus-dia da cultivar Niagara Rosada com os porta-enxertos 'IAC 572' e 'IAC 571-6', e a menor, com o porta-enxerto 'IAC 766'. Evidenciou-se a influência do clima na duração dos estádios fenológicos da videira.

Termos para indexação: vitis, clima, fenologia, porta-enxerto.

\section{PHENOLOGY AND ACCUMULATION OF DEGREES-DAYS OF' 'NIAGARA ROSADA' GRAPEVINE GROWN IN NORTHWESTERN SÃO PAULO STATE}

\begin{abstract}
This work aimed to evaluate the influence of the rootstocks 'IAC 766', 'IAC 572', 'IAC 313' and 'IAC 571-6' in the duration of phenological stages and in the accumulation of degree-days for 'Niagara Rosada' grapevine grown in Votuporanga, SP, Brazil. The statistical design was completely randomized blocks with split plots and five replications, the plot represented by the rootstocks and the subplots by two production cycles. After pruning the vine, evaluations were performed for phenological stages, using the criterion of Eichhon \& Lorenz (1984). Based on the phenological stages, we calculated the duration of periods: pruning to budding, pruning to beginning of flowering, pruning to beginning of fruiting, pruning to beginning of ripening of the bunches, pruning to beginning of the harvest. According to the cycle length of the vine and the daily average temperature, the accumulation of degree-days was calculated. It was observed a longer duration of the cycle and accumulation of degree-days for Niagara Rosada with the rootstocks 'IAC 572' and 'IAC 571-6' and a lower duration, with the rootstock 'IAC 766'. The influence of climate on the duration of phenological stages of grapevine was showed.
\end{abstract}

Index terms: vitis, climate, phenology, rootstocks.

\section{INTRODUÇÃO}

O Brasil é o décimo nono produtor mundial de uva (FAOSTAT, 2009) com produção de 1.295 .442 toneladas em uma área de 83.718 ha (IBGE, 2010). O Estado de São Paulo produz 177,5 mil toneladas, de uva, ocupando a segunda posição no contexto nacional, destacando-se, no entanto, como maior produtor nacional de uvas para mesa (IBGE 2010). A cultivar de uva comum para mesa, representada pela 'Niagara Rosada', corresponde a 48,2\% da produção de uva no Estado (INSTITUTO DE ECONOMIA AGRÍCOLA, 2010).

No Noroeste do Estado de São Paulo, destacam-se os municípios de Jales, Urânia, Palmeira D’Oeste, Marinópolis, São Francisco, dentre outros, os quais respondem por $2,0 \%$ da produção estadual de 'Niagara Rosada' (INSTITUTO DE ECONOMIA

\footnotetext{
${ }^{1}$ Trabalho Sinfruit 004 - Simpósio Internacional de Fruticultura - Avanços na Fruticultura (17 a 21 Outubro) ${ }^{2}$ Pesquisador Científico do Centro de Frutas do Instituto Agronômico (IAC) - 13214-820 - Jundiaí, São Paulo, Brasil. E-mail: tecchio@iac.sp.gov.br; mmterra@iac.sp.gov.br; mouram@iac.sp.gov.br, ejppires@ iac.sp.gov.br
} 
AGRÍCOLA, 2010). No entanto, verifica-se, nos últimos anos, forte tendência no aumento da área plantada dessa cultivar, em virtude do menor custo de produção e maior preço de revenda, quando comparado às cultivares de uva fina para mesa. Estima-se que a área ocupada por esta cultivar na região é de, aproximadamente, 200 ha. Ressalta-se que o melhor preço de revenda deve-se à época de colheita, realizada na entressafra da região de Jundiaí, considerada a região tradicional de cultivo e o maior polo produtor de 'Niagara Rosada' no Estado de São Paulo.

Encontram-se na literatura inúmeros trabalhos relacionados à fenologia da cultivar Niagara Rosada (PEDRO JÚNIOR et al., 1993; PEDRO JÚNIOR et al., 1994; FERRI, 1994; GUERREIRO, 1997, SILVA et al., 1990; ALVARENGA et al., 2002; ANZANELLO et al., 2008; RIBEIRO et al., 2009; TOFANELLI et al., 2011), não havendo, no entanto, informações relacionadas à influência do porta-enxerto na duração das fases fenológicas, nas condições de cultivo da região noroeste do Estado de São Paulo.

De acordo com Pedro Júnior et al. (1993), a fenologia desempenha importante função na avaliação do comportamento de cultivares de videira, permitindo a caracterização da duração das fases fenológicas da videira em relação ao clima, além de ser utilizada para interpretar como as diferentes regiões climáticas interagem com a cultura. A caracterização fenológica e a quantificação das unidades térmicas necessárias para a videira completar as diferentes fases do ciclo produtivo fornecem ao viticultor o conhecimento das prováveis datas de colheita, indicando o potencial climático das regiões para o cultivo da videira. Sentelhas (1998) afirma que o índice térmico, também conhecido como graus-dia, em função da simplicidade e confiabilidade que apresenta, tem sido o mais utilizado na viticultura tropical.

Avaliando o comportamento da cv. Niagara Rosada em diferentes épocas de poda, Pedro Júnior et al. (1993) constataram que, nas podas mais tardias realizadas em $1^{\circ}$ de setembro, o ciclo da cultura foi 116 dias, nas regiões de Tietê e Mococa, enquanto podas realizadas em 15 de julho tiveram um ciclo de 199 dias em São Roque. Os mesmos autores verificaram que a duração das fases fenológicas variou em função do local e da época de poda, e a necessidade térmica da videira foi de 1.248 para 1.386 graus-dia. Ferri (1994) observou, na região de Jundiaí, ciclo produtivo médio de 159 dias e uma necessidade térmica de 1.589 graus-dia. Alvarenga et al. (2002), ao avaliarem a fenologia da cv. Niagara Rosada em Caldas, Minas Gerais, observaram maior duração do ciclo com os porta-enxertos 'IAC 572' e 'IAC 313' quando comparado com os porta-enxertos 'Ripária do Traviú' e 'IAC 766'. Anzanello et al. (2008), em experimento realizado em Eldorado do Sul-RS, obtiveram com a cv. Niagara Rosada duração do ciclo fenológico de 156 e 116 dias, e acúmulo de graus-dia de 1.422 e 1.602 , respectivamente, em podas realizadas no inverno e no verão. Ribeiro et al. (2009) obtiveram, com a videira 'Niagara Rosada' cultivada em Janaúba-MG, duração no ciclo da poda à colheita de 116 dias para a poda realizada em janeiro e de 123 dias para a poda em julho. Quanto à necessidade térmica, as plantas acumularam 1.838 e 1.766 graus-dia, respectivamente, na poda realizada em janeiro e julho. Tofanelli et al. (2011), em experimento realizado em Goiás, verificaram duração do ciclo da videira 'Niagara Rosada' com os porta-enxertos 'Ripária do Traviú', 'IAC 766' e 'IAC 572' de, respectivamente, 109; 112 e 113 dias, e acúmulo de graus-dia de, respectivamente, 1.167; 1.198 e 1.207 .

Este trabalho teve a finalidade de avaliar a influência do porta-enxerto na fenologia da videira 'Niagara Rosada' cultivada em Votuporanga, município pertencente à região noroeste do Estado de São Paulo.

\section{MATERIAL E MÉTODOS}

Realizou-se o experimento em Votuporanga, no Estado de São Paulo, Brasil. A área experimental situa-se a $20^{\circ} 15^{\prime} \mathrm{S}$. e $50^{\circ} 30^{\prime} \mathrm{O}$. e $483 \mathrm{~m}$ de altitude, apresentando como indicadores climáticos precipitação pluvial anual média de $1.312 \mathrm{~mm}$ e temperatura média mensal de $23,6^{\circ} \mathrm{C}$.

$\mathrm{O}$ vinhedo experimental estava sustentado em pérgula, no espaçamento de $2,0 \times 2,0 \mathrm{~m}$. Os tratamentos consistiram na combinação da cv Niagara Rosada sobre os porta-enxertos 'IAC 766', 'IAC 572', 'IAC 313' e 'IAC 571-6'. Os porta-enxertos 'IAC 766' (106-8 Mgt x Vitis caribaea), 'IAC 572' (Vitis caribaea e RR 101-14 Mgt), 'IAC 313' (Golia $\mathrm{x}$ V. cinerea) e 'IAC 571-6' (Vitis caribaea $\mathrm{x}$ Pirovano 57) foram obtidos por Santos Neto, no programa de melhoramento genético do Instituto Agronômico de Campinas (IAC). Apresentam como principais características alto vigor vegetativo, ótimo enraizamento das estacas e aptos às condições subtropicais e tropicais do Brasil.

Cada parcela experimental foi composta por 4 plantas. Avaliaram-se duas podas de produção, sendo as podas realizadas em 18-08-2009 e 03-08-2010. $\mathrm{O}$ delineamento estatístico utilizado foi em blocos inteiramente casualizados, com parcelas subdivididas, dez repetições, sendo as parcelas representadas 
pelos porta-enxertos, e as subparcelas, pelos ciclos de produção.

Após a poda da videira, avaliaram-se os estádios fenológicos da cv. 'Niagara Rosada', utilizando-se do critério de Eichhon e Lorenz (1984), realizando as anotações duas vezes por semana, até o florescimento e, posteriormente, uma vez por semana. Baseado nos estádios fenológicos, calculou-se a duração dos períodos: poda ao início da brotação; poda ao início do florescimento; poda ao início da frutificação; poda ao início da maturação dos cachos; poda ao início da colheita.

Para a caracterização das exigências térmicas, calculou-se o somatório de graus-dia desde a poda até a colheita, utilizando-se da temperatura-base de $10^{\circ}$ C (PEDRO JÚNIOR et al., 1994), segundo equação proposta por Winkler (1948), citado por Hidalgo (1993)

$\mathrm{GD}=\sum\left(\mathrm{Tm}-10^{\circ} \mathrm{C}\right) \times \mathrm{n}^{\circ}$ dias da poda à colheita Em que: GD - graus-dia;

Tm - Temperatura média diária.

Os dados de temperatura foram obtidos por uma Estação meteorológica automática, marca Campbell Scientific instalada no interior da área experimental.

Os dados foram submetidos à análise de variância e teste Tukey, a 5\% de significância.

\section{RESULTADOS E DISCUSSÃO}

Pelos resultados obtidos, verificou-se efeito dos porta-enxertos e das épocas de poda para a duração das fases fenológicas, em dias, e do acúmulo de graus-dia na videira 'Niagara Rosada' (Tabela 1). Na média dos dois ciclos de produção (Tabela 2), obteve-se maior duração das fases fenológicas com a videira 'Niagara Rosada' enxertada nos porta-enxertos 'IAC 572' e 'IAC 571-6', sendo que as maiores variações ocorreram no período compreendido entre à poda ao início da maturação e da poda a colheita. Com a cv. Niagara Rosada enxertada sobre o porta-enxerto 'IAC 572' houve acréscimo no período da poda ao início da maturação e da poda à colheita de, respectivamente, 6 e 11 dias, quando comparado com os valores obtidos com a videira 'Niagara Rosada' enxertada sobre o porta-enxerto 'IAC 766'. Estes resultados estão de acordo com Alvarenga et al. (2002), que também obtiveram maior duração de ciclo da videira 'Niagara Rosada' enxertada sobre o porta-enxerto 'IAC 572', quando comparado ao porta-enxerto 'IAC 766'. Essas variações na duração dos estádios fenológicos estão relacionadas ao vigor que o porta-enxerto proporciona à copa.

O maior acúmulo de graus-dia da poda à colhei- ta foi obtido com a cv. Niagara Rosada enxertada sobre os porta-enxertos 'IAC 572' e 'IAC 571-6', obtendo-se valores de, respectivamente, 1.741 e 1.735 . O menor acúmulo de graus-dia da videira foi proporcionado pelo porta-enxerto 'IAC 766', sendo 9\% inferior quando comparado com a 'Niagara Rosada' enxertada sobre o 'IAC 572'. Estes resultados condizem com os obtidos por Tofanelli et al. (2011), que, em condições de clima mais quente, também observaram variações no acúmulo de graus-dia na videira 'Niagara Rosada' com os porta-enxertos 'IAC 766' e 'IAC 572' sendo de, respectivamente, 1.198 e 1.207 .

As variações obtidas no acúmulo de graus-dia da poda à colheita foram de 1.589 a 1.741. Esses resultados estão de acordo com os limites encontrados para a 'Niagara Rosada' cultivada em diversas regiões. Na Califórnia, Winkler (1965) obteve variações de 1.372 a 2.205 graus-dia; na Austrália, Cirami e Furkaliev (1991) obtiveram variações de 1.642 a 2.228 graus-dia; em Jundiaí, Pedro Júnior et al. (1994) obtiveram limites de 1.459 a 1.929 graus-dia; em Janaúba, Minas Gerais, Ribeiro et al. (2009) obtiveram variações no acúmulo de graus-dia de 1.766 a 1.838 .

Referente aos ciclos de produção, obteve-se maior duração nos períodos da poda à brotação, poda ao florescimento e da poda ao início do florescimento da videira 'Niagara Rosada' no ciclo de produção de 2010 (Tabela 3), devendo-se às menores temperaturas mínimas quando comparado com o ciclo de produção de 2009 (Figura 1A).

No entanto, em função da redução nos períodos da poda à maturação e da poda à colheita, obteve-se menor duração do ciclo da videira 'Niagara Rosada' ano de 2010. Esses resultados devem-se aàs variações médias da temperatura (Figura 1B) e da radiação global (Figura 2) verificadas durante a realização do experimento. Notou-se que, no ano de 2010 , os valores médios da temperatura e radiação global durante o ciclo da videira foram superiores quando comparada com o ano de 2009. Com o aumento da temperatura e radiação global, houve redução no ciclo médio da videira 'Niagara Rosada' de 120 para 115 dias, respectivamente, nos ciclos de produção de 2009 e 2010. De acordo com Leão e Silva (2003), a videira é condicionada pela disponibilidade térmica para completar seu ciclo, o que pôde ser comprovado pela redução na duração do ciclo de produção de 2010 .

Salienta-se que a caracterização fenológica para a videira completar as diferentes fases do ciclo produtivo fornecem ao viticultor o conhecimento das prováveis datas de colheita e tratamentos fitossanitários, indicando o potencial climático das regiões para o cultivo da videira. 
TABELA 1 - Valores do Teste F da análise de variância, da duração dos estádios fenológicos da poda ao início da brotação, poda ao início do florescimento, poda ao início da frutificação, poda ao início da maturação, poda à colheita e do acúmulo de graus-dia da videira 'Niagara Rosada' enxertada em diferentes porta-enxertos, em dois ciclos de produção. Votuporanga, 2009/2010.

\begin{tabular}{ccccccc}
\hline $\begin{array}{c}\text { Fontes de } \\
\text { Variação }\end{array}$ & Brotação & Florescimento & $\begin{array}{c}\text { Frutificação } \\
\text { Dias }\end{array}$ & Maturação & $\begin{array}{c}\text { Colheita } \\
\text { Acúmulo } \\
\text { Graus- dia (GD) }\end{array}$ \\
\hline Bloco & $0,9^{\mathrm{NS}}$ & $1,8^{\mathrm{NS}}$ & $1,4^{\mathrm{NS}}$ & $3,0^{*}$ & $3,5^{* *}$ & $3,4^{* *}$ \\
Porta-enxerto (PE) & $54,8^{* *}$ & $9,4^{* *}$ & $7,9^{* *}$ & $3,2^{*}$ & $14,8^{* *}$ & $14,2^{* *}$ \\
Ciclos (C) & $93,8^{* *}$ & $254,1^{* *}$ & $244,8^{* *}$ & $20,9^{* *}$ & $13,7^{* *}$ & $22,3^{* *}$ \\
Interação (PE x C) & $1,6^{\mathrm{NS}}$ & $6,0^{\mathrm{NS}}$ & $3,2^{\mathrm{NS}}$ & $1,5^{\mathrm{NS}}$ & $1,3^{\mathrm{NS}}$ & $1,5^{\mathrm{NS}}$ \\
CV (a) & 6,3 & 3,8 & 4,3 & 6,9 & 4,4 & 5,0 \\
CV (b) & 8,6 & 3,9 & 3,8 & 6,7 & 4,5 & 5,2 \\
Média & 16,0 & 33,2 & 38,4 & 96,8 & 118,0 & 1682,7 \\
\hline Ns = não significativo; * = significativo a 5 \% de significância; ** = significativoa 1 \% de significância pelo teste $\mathrm{F}$.
\end{tabular}

TABELA 2 - Resultados médios da duração, em dias, dos estádios fenológicos da poda ao início da brotação, poda ao início do florescimento, poda ao início da frutificação, poda ao início da maturação, poda à colheita e do acúmulo de graus-dia da videira 'Niagara Rosada' enxertada em diferentes porta-enxertos, em dois ciclos de produção. Votuporanga, 2009/2010.

\begin{tabular}{ccccccc}
\hline Porta-enxerto & Brotação & Florescimento & $\begin{array}{c}\text { Frutificação } \\
\text { Dias }\end{array}$ & Maturação & Colheita & $\begin{array}{c}\text { Acúmulo } \\
\text { Graus-dia (GD) }\end{array}$ \\
\hline 'IAC 313' & $14,4 \mathrm{C}$ & $32,4 \mathrm{~B}$ & $37,4 \mathrm{~B}$ & $95,6 \mathrm{AB}$ & $117,0 \mathrm{~B}$ & $1666,4 \mathrm{~B}$ \\
'IAC 572' & $17,8 \mathrm{~A}$ & $33,6 \mathrm{~A}$ & $39,2 \mathrm{~A}$ & $100,1 \mathrm{~A}$ & $121,2 \mathrm{AB}$ & $1734,5 \mathrm{AB}$ \\
'IAC 571-6' & $16,9 \mathrm{~B}$ & $34,2 \mathrm{~A}$ & $39,3 \mathrm{~A}$ & $97,7 \mathrm{AB}$ & $121,6 \mathrm{~A}$ & $1740,8 \mathrm{~A}$ \\
'IAC 766' & $14,8 \mathrm{C}$ & $32,5 \mathrm{~B}$ & $37,6 \mathrm{~B}$ & $94,0 \mathrm{~B}$ & $112,0 \mathrm{C}$ & $1589,2 \mathrm{C}$ \\
\hline DMS & 0,9 & 1,1 & 1,4 & 5,8 & 4,5 & 72,7 \\
\hline
\end{tabular}

Médias seguidas de letras diferentes diferem entre si, pelo teste de Tukey, ao nível de 5\% de probabilidade.

TABELA 3 - Resultados médios da duração dos estádios fenológicos, em dias, da poda ao início da brotação, poda ao início do florescimento, poda ao início da frutificação, poda ao início da maturação, poda à colheita e do acúmulo de graus-dia da videira 'Niagara Rosada' enxertada em diferentes porta-enxertos, nos ciclos de produção de 2009 e 2010. Votuporanga, 2009/2010.

\begin{tabular}{ccccccc}
\hline $\begin{array}{c}\text { Ciclo de } \\
\text { Produção }\end{array}$ & Brotação & Florescimento & $\begin{array}{c}\text { Frutificação } \\
\text { (Dias) }\end{array}$ & Maturação & Colheita & $\begin{array}{c}\text { Acúmulo } \\
\text { Graus-dia (GD) }\end{array}$ \\
\hline 2009 & $14,5 \mathrm{~B}$ & $30,9 \mathrm{~B}$ & $35,9 \mathrm{~B}$ & $100,2 \mathrm{~A}$ & $120,2 \mathrm{~A}$ & $1728,8 \mathrm{~A}$ \\
2010 & $17,5 \mathrm{~A}$ & $35,5 \mathrm{~A}$ & $40,9 \mathrm{~A}$ & $93,5 \mathrm{~B}$ & $115,4 \mathrm{~B}$ & $1636,6 \mathrm{~B}$ \\
\hline DMS & 0,6 & 0,6 & 0,7 & 2,9 & 2,4 & 39,6 \\
\hline
\end{tabular}

Médias seguidas de letras diferentes diferem entre si, pelo teste de Tukey, ao nível de 5\% de probabilidade. 

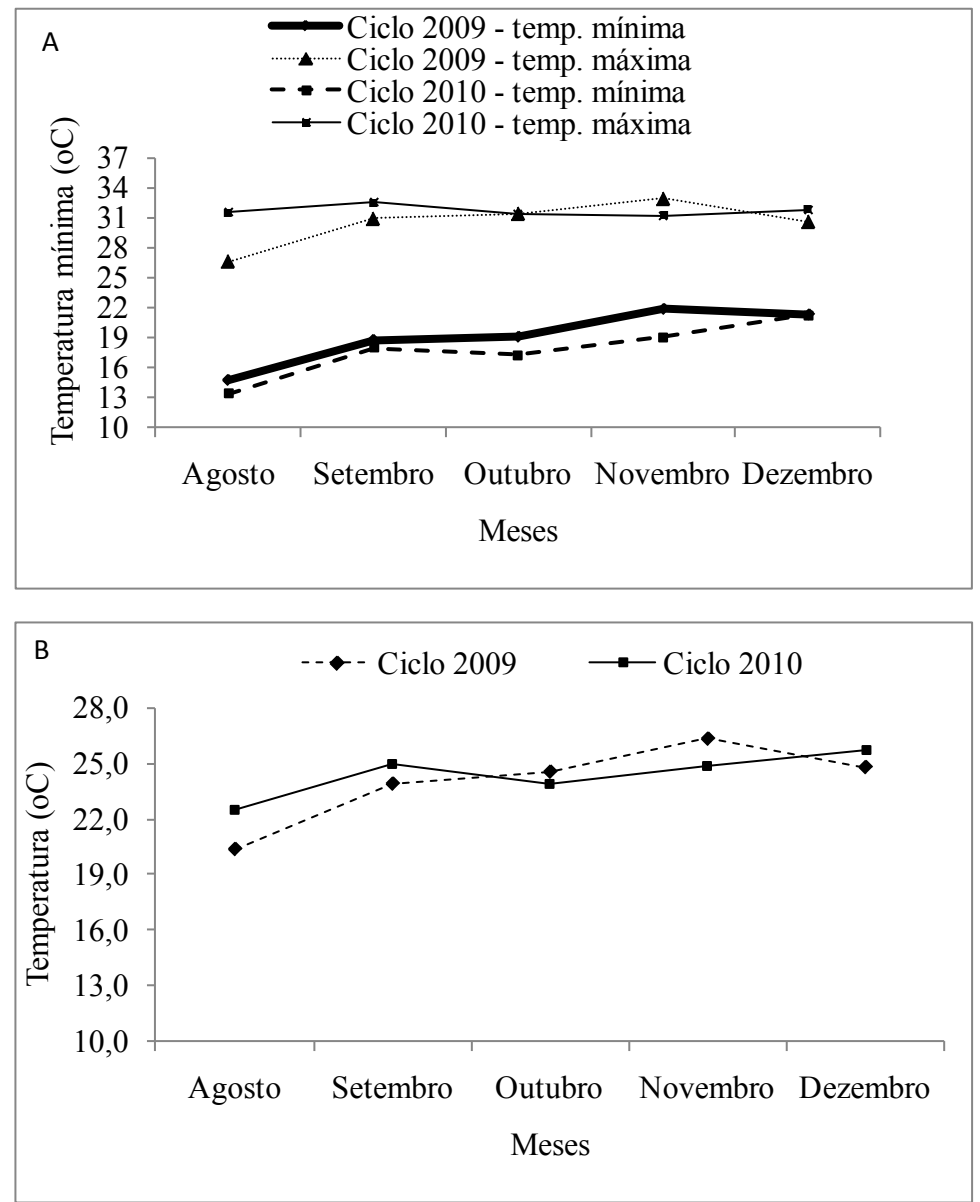

FIGURA 1-Temperatura mínima, máxima (A) e média (B) mensal durante os ciclos de produção de 2009 e 2010. Votuporanga, 2009/2010

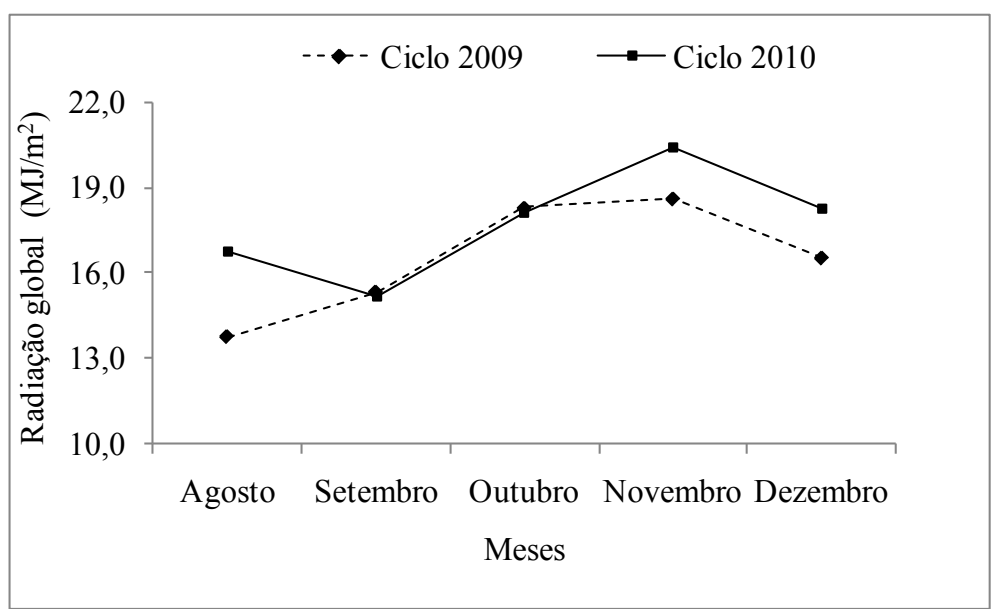

FIGURA 2 - Radiação global média mensal durante os ciclos de produção 2009 e 2010. Votuporanga,de 2009/2010. 


\section{CONCLUSÃO}

A maior duração do ciclo e do acúmulo de graus-dia da cv. Niagara Rosada foi obtida com os porta-enxertos 'IAC 572' e 'IAC 571-6', obtendo-se os menores valores com o porta-enxerto 'IAC 766'. Evidenciou-se a influência dos dados climáticos na fenologia da videira e a possibilidade do escalonamento da época de produção com porta-enxertos que induzam à copa maior precocidade, sendo um aspecto de interesse ao viticultor.

\section{AGRADECIMENTOS}

À FAPESP, pelo auxílio concedido para a realização do experimento.

Ao Técnico de Apoio do Polo Regional do Noroeste Paulista, Sr. Isaac Jesus de Souza, pelo auxílio na realização do experimento.

\section{REFERÊNCIAS}

ALVARENGA, A. A.; REGINA, M. A.; FRAGUAS, J. C.; CHALFUN, N. N. J.; SILVA, A. L. Influência do porta-enxerto sobre o crescimento e produção da cultivar de videira Niagara Rosada (Vitis labrusca L. x Vitis vinifera L.), em condições de solo ácido. Ciência e Agrotecnologia, Lavras, p.1459-1464. 2002. Número Especial

ANZANELLO, R.; SOUZA, P. V. D.; GONZATTO, M. P. Produção de videiras 'Niagara Branca' e 'Concord' submetidas a duas safras por ciclo vegetativo na depressão central do Rio Grande do Sul. Scientia Agrária, Curitiba, v. 9, n. 3, p. 311-316, 2008.

CIRAMI, U. A.; FURKALIEV, D. G. Effect of time of pruning and hydrogen cyanamide on growth and development of glasshouse-grown Cardinal grapes. Australian Journal of Experimental Agriculture, East Melbourne, v. 31, n. 2, 273-278, 1991.

EICHORN, K.W.; LORENZ, D.H. Phaenologische Entwicklungsstadien der Rede. European and Mediterranean Plant Protection Organization, Paris, v. 14, n. 2, p. 295-298, 1984.

FAO. Faostat agriculture data - croops and processed - grape and wine. Disponível em: $<\mathrm{http}: /$ www.faostat.fao.org>. Acesso em: maio de 2010.
FERRI, C. P. Caracterização agronômica e fenológica de cultivares e clones de videira (Vitis spp) mantidos no Instituto Agronômico, Campinas-SP. 1994. 89f. Dissertação (Mestrado em Fitotecnia) Escola Superior de Agricultura "Luiz de Queiroz", Universidade de São Paulo, Piracicaba, 1994.

GUERREIRO, V. M. Avaliação fenológica da videira (Vitis labrusca L. x Vitis vinifera L.) cultivar Niagara Rosada na região de Selvíria - MS. 1997. 98f. Dissertação (Mestrado em Sistema de Produção) - Faculdade de Engenharia, Universidade Estadual Paulista, Ilha Solteira, 1997.

HIDALGO, L. Tratado de viticultura. Madrid: Mundi, 1993. 983p.

INSTITUTO DE ECONOMIA AGRICOLA - IEA. Levantamento de área e produção dos principais produtos da agropecuária do Estado de São Paulo. São Paulo: IEA/CATI, 2010. Disponível em $<$ http://ciagri.iea.sp.gov.br/bancoiea $>$. Acesso em: 20 maio 2011.

INSTITUTO BRASILEIRO DE GEOGRAFIA E ESTATÍSTICA. Produção agrícola. Disponível em: $<$ http://www.ibge.gov.br>. Acesso em: 2 ago. 2010.

LEÃO, P. C. S. de; SILVA, E. E. G. Caracterização fenológica e requerimento térmico de variedades de uvas sem semente no Vale do São Francisco. Revista Brasileira de Fruticultura, Jaboticabal, v. 25, n. 3, p. 379-382, 2003.

PEDRO JÚNIOR, M.J.; SENTELHAS, P.C.; POMMER, C.V.; MARTINS, F.P.; GALLO, P.B.; SANTOS, R.R. dos; BOVI, V.; SABINO, J.C. Caracterização fenológica da videira 'Niagara Rosada' em diferentes regiões paulistas. Bragantia, Campinas, v.52, n.2. p. 153-160, 1993.

PEDRO JÚNIOR, M. J.; SENTELHAS, P. C.; POMMER, C. V.; MARTINS, F. P. Determinação da temperatura-base, graus-dia e índice biometeorológico para a videira 'Niagara Rosada'. Revista Brasileira de Agrometeorologia, Santa Maria, v. 2, p. 51-56, 1994. 
RIBEIRO, D. R.; CORSATO, C. E.; LEMOS, J. P.; SCARPARE FILHO, J. A. Desenvolvimento e exigência térmica da videira 'Niagara Rosada', cultivada no norte de Minas Gerais. Revista Brasileira de Fruticultura, Jaboticabal, v. 31, n. 3, p. 890-895, 2009.

SENTELHAS, P. C. Aspectos climáticos para a viticultura tropical. Informe Agropecuário, Belo Horizonte, v. 19, n. 194, p. 9-14, 1998.

SILVA, A. C.; PEREIRA, F. M.; MARTINS, F. P. Comportamento de cultivares americanas de videira na região de Jundiaí - SP. Científica, Jaboticabal, v.18, n.1, p.61-70, 1990.
TOFANELLI, M. B. D.; BOTELHO, R. V.; PIRES, E. J. P.; VILELA, L. A. F.; RIBEIRO, D. O. Phehology of "Niagara Rosada" grepevines grafted on different rootstocks grown on Cerrado (Brazilian savanna) of Goiás State, Brazil. African Journal of Biotechnology, Bowie, v. 10, n. 17, p. 3387 $3392,2011$.

WINKLER. A. L. Viticutura. México: Compania Editorial Continental, 1965. 792p. 